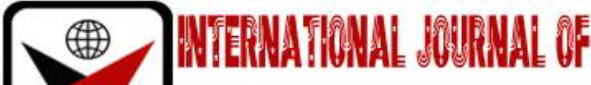

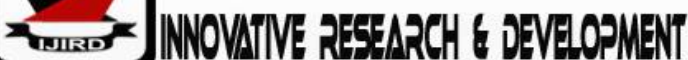

ISSN 2278-0211 (Online)

\section{Assessing the Factors Influencing the Performance of Small and Medium Scale Enterprises in Tamale Metropolis}

\author{
Alhassan Yahaya \\ Lecturer, Department of Hospitality and Tourism Management, \\ Tamale Technical University, Ghana
}

\begin{abstract}
:
The study was aimed at assessing the factors influencing the performance of Small and Medium Scale Enterprises in the Tamale Metropolis. In order for SMEs to achieve their desired objectives, there is the need for a thorough investigation to unearth those factors that affect their performance. Therefore, this study sought to examine the nature of funding for the SMEs as well as the challenges facing these SMEs in the Tamale Metropolis. The study adopted a descriptive research design to assess the factors influencing the performance of SMEs in the Tamale metropolis. The study relied on systematic and purposive sampling techniques in selecting a total of 235 respondents for the study. It was revealed from the study that most of the SMEs in the Tamale metropolis were funded basically from personal savings of the owners. It was also revealed that SMEs did not get the needed support or incentives from Government and other relevant stakeholders in the Metropolis. The study further revealed that SME operators had difficulty in accessing credit from the mainstream commercial banks and other credit lending institutions as a result of collateral requirements and other bureaucratic procedures involved. The study concluded that lack of access to credit from the mainstream commercial banks and other credit lending institutions, coupled with high interest rates and taxes on goods and services adversely affected the performance of SMEs in the Tamale metropolis. The study also concluded that lack of Government support for SME operators in the metropolis was also responsible for their abysmal performance. The study recommended capacity building for SME operators to enhance their business management and entrepreneurial skills to enable them identify and exploit business opportunities locally and internationally.
\end{abstract}

Keywords: Performance, Small and Medium Scale Enterprises (SMEs), SME Operators, Tamale Metropolis, Stakeholders

\section{Introduction}

Worldwide, the contribution of Small and Medium Scale Enterprises (SMEs) to the growth and development of national economies cannot be over emphasized. SMEs form a fundamental portion of the economic fabric in both developed and developing countries, and they play a crucial role in furthering growth, innovation and prosperity. Small, and medium enterprises (SMEs) all around the world have been recognised as the key engine to economic development because they create almost half of the new jobs in the world's economy (Edmiston, 2007). According to Kongolo (2010), SMEs play a significant role in terms of contributing to the economic progress of many nations around the world. Data from both the developed as well as developing countries has revealed that the SME sub- sector is an active and vibrant force required for economic growth, innovation as well as job creation (Chodokufa, 2009; Andzelic et al., 2011).

Even though, up-to-date data tend to be difficult to obtain, estimates suggest that more than $95 \%$ of enterprises across the world are SMEs, creating approximately 60\% of private sector employment (Ayyagari et al. 2011). Japan has the maximum proportion of SMEs among the industrialized nations, accounting for more than 99\% of total businesses (EIU, 2010). India, according to its Ministry of Micro, Small and Medium Enterprises, recorded 13 million SMEs in 2008, equal to $80 \%$ of all the country's businesses (Ghatak, 2010). In South Africa, it is estimated that $91 \%$ of the registered business entities are SMEs (Abor and Quartey, 2010).

Estimated data for the twenty-seven countries in the European Union (the EU-27) with regard to 2012 also showed the importance of SMEs for their economies. They account for $99.8 \%$ of most enterprises, employing $67 \%$ of all workers as well as contribute $58 \%$ of gross value added (GVA) - defined as the value of their outputs much less the value of intermediate consumption and an important factor within GDP.

The contribution made by SMEs really does vary widely between countries and regions. Nevertheless, although they play particularly key functions in high-income countries, they are also vital in low-income countries, as they make significant contribution to both GDP and employment (Dalberg, 2011).

In developing countries, SMEs are important because they do not only create jobs but also, they create employment for the unskilled workforce who happens to be overly abundant (Phillips \& Bhatia-Panthaki, 2007). Kongolo (2010) indicates that SMEs in South Africa represent about 91\% of formal businesses, providing almost $60 \%$ of jobs and contributing about $51 \%$ to $57 \%$ of GDP. 
SMEs are also major contributors to innovation in many economies, partly due to their collaboration with the larger corporate sector. SMEs that become part of the supply chains of larger businesses can be spurred on to improve their own human and technological capital (ACCA, 2010), thus improving their own efficiency and performance.

In Ghana, it is estimated that SMEs offer about $85 \%$ of manufacturing employment, account for $90 \%$ of existing businesses in the country, and contributed 49\% to the country's GDP in 2012. They contribute to job creation, provision of basic goods and services, and generation of foreign trade and tax revenues for national socio-economic development (Ghana Banking Survey, 2013).

A survey conducted by the Korean Development Institute (KDI) in Sept 2008 on "Building the actual Foundations for the Development of SME in Ghana") noted grimly, the obstacles that SMEs face daily in Ghana. The study listed these as smaller sizes of the SMEs; they are few in number and less competitive internationally. These factors affect the SMEs in many ways. For instance, over $80 \%$ of SMEs in Ghana are reportedly having workers numbering less than ten. The smaller size of these types of SMEs means less value addition because fewer processes are possibly involved in the production.

SMEs are also critically challenged in terms of human resources as a significant number of them are not able to employ highly qualified personnel to occupy key positions so as to inject professionalism into the operations of these SMEs. Access to medium to long-term funding necessary for capital investment is also a major headache to many an SME in the region.

Notwithstanding the numerous challenges confronting these enterprises, they continue to occupy a place of pride in virtually every country or state. Due to the significant roles played by SMEs within the development and growth of various economies, these SMEs are often been referred to as the engines of growth and drivers for socio-economic transformation of any country. SMEs contribute significantly to the economic diversification, exports, social cohesion, and also constitute a feeder line for the corporations of the future as it is from among them that most Multi-national companies (MNCS) and large companies emerge. As such, SME development serves as a vital instrument in poverty reduction and sustained economic development efforts. SMEs can also be used as a tool in controlling rural urban drift, enhancement of standard of living of the employees from the SMEs and their dependents as well as those who are indirectly associated with them (Kongolo, 2010; Edmiston, 2007).

In line with the positive contributions of the SME sub-sector to the economy of Ghana, successive Governments have made conscious efforts by way of establishing organizations, policy initiatives and programmes aimed at offering support to SMEs in the country at both national, regional and at the district levels. Examples of these institutions and programmes include National Board for Small Scale Enterprises, Economic Recovery Programme, Export Development and Agricultural Investment Fund, Ghana youth employment and entrepreneurial development Agency, Savanna Accelerated Development Authority, Central Region Development Commission to mention but a few (Darko \& Koranteng, 2015).

In the Northern Region in particular, there are a number of NGOs operating individually or in partnership with Government to provide backing to good number of SME operators. Notably among them include, Campaign for Female Education, Canadian International Development Agency, Danish International Development Agency, United States of America International Development, Germany Development Corporation, Resiliency in Northern Ghana, TECHNOSERVE, and so on. These organizations either offer financial, technical or logistical support to SMEs in the Region with the sole aim of improving their entrepreneurial prospects. There are also a number of banking institutions which provide loan funds at affordable interest rates and repayment terms. Some of these banking institutions are Bonzali Rural Bank, Bayport Financial Services, African Financial Services, and IZWE Loans etc. (IFAD, 2015; Darko and Koranteng, 2015).

Despite the existence of many SME support programmes and initiatives by both Government and Nongovernmental Organizations to SMEs, SMEs in the region are still bedeviled with a number of challenges. Only a few of them are recording positive gains in their businesses. A significant number of them are folding up. The failure rate particularly among the start-ups is alarmingly high in the Region.

This raises a question on whether the SME owner/managers have the adequate and requisite abilities and competences to manage the SMEs in a manner that enhances growth and survival or not. Similarly, is it that the various policy interventions by both Government and Non-governmental Organizations are ineffective? Could it also be that SME operators in the region are financially constraint to the extent that they cannot operate at their optimum levels?

It was against this background that the study sought to examine the nature of funding for small and medium scale enterprises as well as assesses the challenges facing these Small and Medium Scale enterprises in the Tamale Metropolis.

\section{Literature Review}

\subsection{Definition and Scope of SMEs}

The definition of SMEs remains a contention as different authors and researchers have different views of what constitute SMEs (Cofie, 2012). Katau (2014) indicates that definition of the term depends on the individual or body defining it as well as where they are being defined. According to him, the same person may define the term differently depending on where they are. Although the concept defies a universally acceptable definition, it is agreed that the understanding of it could lead one into two major folds. Namely: the quantitative and qualitative definitions. The most commonly used definitions are those by international institutions such as European Commission (EC), Multilateral Investment Guarantee Company (MIGA)/International Finance Corporation (IFC), Asia Pacific Economic Cooperation (APEC), and United Nations International Development Organization (UNIDO).

The definition by the European Commission (EC) takes into consideration three indicators which include staff headcounts, annual sales as well as value of assets. This quantitative definition by the EC considers SMEs as those 
corporations that have staff capacity of less than two hundred and fifty people and have annual sales value not exceeding $\$ 67$ million and/or total assets value not exceeding \$56 million.

It also described Small enterprises as those enterprises which have staff capacity of less than 50 individuals and with annual sales or total Asset value not exceeding \$13 million. Micro enterprises are also defined as those businesses which employ lower than 10 persons and with annual sales or even total assets that do not exceed \$3 million. The Table below depicts the actual threshold of staff, annual sale as well as total assets considered in the definition of SMEs by the EC.

\begin{tabular}{|c|c|c|c|}
\hline $\begin{array}{l}\text { Enterprise } \\
\text { Category }\end{array}$ & Headcount (Annual Work Unit) & Annual Sales & Total Assets \\
\hline Mlicro & $<10$ & $\leq \$ 3$ million & $\leq \$ 3$ million \\
\hline Small & $<50$ & $\leq \$ 13$ million & $\leq \$ 13$ million \\
\hline Medium Sized & $<250$ & $\leq \$ 67$ million & $\leq \$ 56$ million \\
\hline
\end{tabular}

Table 1: The European Commission Enterprise Categories Source: Adopted from European Commission, 2005

According to MIGA and IFC, SMEs are those enterprises which have staff strength of less than 50 workers and have annual turnover not exceeding $\$ 3$ million and/or total assets not exceeding \$3million. An enterprise must fulfil at least two of the above criteria in order to qualify as an SME.

It also defined Medium Enterprises as those businesses that have staff capacity of less than 300 persons and with yearly sales or total assets that do not exceed $\$ 15$ million.

Any enterprise which meets at least two of the above criteria is actually qualified to be a medium enterprise.

The definition by Asia and Pacific Economic Cooperation (APEC) considered the number of personnel employed within the business as an important criterion, and therefore defined SMEs as enterprises with less than 100 employees. APEC also defined medium sized enterprises as businesses with a staff capacity of between 20 and 99 people. Small firms are defined to be the enterprises with a staff capacity of between five and nineteen while micro firms are those business with less than 5 employees.

The United Nations International Development Organization (UNIDO) definition of SMEs not only considered the quantitative dimension but also emphasised the need to incorporate the qualitative indicators. In addition to quantitative criteria, UNIDO emphasised the need to consider a host of qualitative criteria as shown in the Table below.

\begin{tabular}{|c|c|c|}
\hline Category & SMEs & Large Companies \\
\hline Management & $\begin{array}{l}\text { Proprietor-entrepreneurship } \\
\text { - Functions linked to personalities }\end{array}$ & $\begin{array}{l}\text { - Manager-entrepreneurship } \\
\text { - Division of labor by subject matters }\end{array}$ \\
\hline Personnel & $\begin{array}{l}\text { - Lack of university graduates } \\
\text { - All-round Knowledge }\end{array}$ & $\begin{array}{l}\text { - Dominance of university graduates } \\
\text { - Specialization }\end{array}$ \\
\hline Organization & - Highly personalized contacts & - Highly formalized communication \\
\hline Sales & $\begin{array}{l}\text { - Competitive position not defined } \\
\text { and uncertain }\end{array}$ & - Strong competitive position \\
\hline Buyer's Relationships & - Unstable & - Based on long-term contracts \\
\hline Production & - Labor intensive & $\begin{array}{l}\text { - Capital intensive, economies of } \\
\text { scale }\end{array}$ \\
\hline Research Development & $\begin{array}{l}\text { Following the market, intuitive } \\
\text { approach }\end{array}$ & - Institutionalized \\
\hline Finance & $\begin{array}{l}\text { Role of family funds, self } \\
\text { financing }\end{array}$ & $\begin{array}{l}\text { Diversified ownership structure, } \\
\text { access to anonymous capital market }\end{array}$ \\
\hline
\end{tabular}

Table 2: Application of Qualitative Indicators for Defining SMEs by UNIDO Source: UNIDO (Cited In USAID, 2007)

Admittedly, the definition of SMEs vary even within countries and in the Ghanaian context, the National Board for Small Scale Industries (NBSSI) and Ghana Statistical Service (GSS) represent the major authorities whose definitions are commonly used. The NBSSI which is an apex body established by Act 434 of 1981 for promotion of small scale industries considers small enterprises as those which have 29 or less employees and enterprises whose capital investment requirement do not exceed the cedi equivalent of $\$ 100,000$ (Boachie-Mensah \& Marfo-Yiadom, 2005). The GSS also considers small enterprises to be firms with the number of employee less than 10 and those with more than 10 employees to be medium and large size enterprises (Kayanula \& Quartey, 2000).

\subsection{Determining SME Performance}

The determination of SME performance is important for a reality check as well as for the SME to be able to measure progress. Performance as defined by Lebas and Euske (2002: 68) means "doing today what is going to lead to 
measured value outcomes tomorrow". Various authors and authorities define performance through different perspective and have offered different measures for performance. Some studies (e.g. Khan, 2010 \& Rauf 2007) have demonstrated that financial, non-financial and operational measurements proved useful in measuring performance. Other studies have used stakeholder theory (Hubbard, 2006) for SME performance measurement. However, this study utilizes the former approach which uses financial, nonfinancial and operational metrics to determine SME overall performance.

\subsection{Characteristics of SMEs in Ghana}

SMEs are differentiated from large firms based on certain key features attributable to SMEs which uniquely distinguish them from larger firms. One characteristic feature which distinguishes SMEs from larger firms is the fact the latter have easy access to foreign and local capital market whilst the former tend to be limited as a result of the higher intermediation costs associated with smaller projects. Also, SMEs are saddled with the same fixed cost as bigger firms especially in complying with regulations even though they have limited capacity to market products overseas (Kayanular \& Quartey, 2000).

Ghanaian SMEs can be classified as urban and rural enterprises. The former can further be split into organised and unorganized businesses. Organised business are those that have employees with a duly registered office and are solely owned by individual whilst the unorganised ones are mostly consist of artisans, who work in open areas, temporal wooden structures, or at home as well as employ little or in some cases no permanent staff. Rural enterprises on the other hand refer to all those businesses which are mostly owned by family members, individual artisans, women who are involved in food processing using local crops.

What constitutes the major activities within this sector include: soap and liquids, fabrics, clothing and tailoring, textile as well as leather, blacksmiths, timber and mining, stones and cement, beverages, food processing, wooden furniture, electronic assembly, agro processing, chemical based products and mechanics (Kayanula \& Quartey, 2000).

The SME sub- sector is characterised by low levels of education and training on the part of the operators rendering them inefficient and less receptive to appropriate technology. The businesses are mostly managed by family members with little or no distinction between the owners and also the business to the extent that the owner operates exactly the same account with the business.

Ghanaian SMEs tend to be heterogeneous in nature. They ranged from small workshops specialising in furniture making, metallic works and clothing to medium-scaled producers of machinery as well as service providers such as restaurants, consulting and computer software firms.

\subsection{Source of Funding for SMEs}

The operation and sustainability of SMEs thrives on the availability of funds. Access to funds could be from national or international sources. Even within the national domain, the sources of funds for a small business are numerous, but however, these can generally be classified into two broad branches. These include internal and external sources. This section will expound on these two categories of funds for SMEs. The internal sources refer to the sources within the business while the external sources refer to those provided outside the business.

\subsubsection{Internal Sources of Funds}

The internal sources of funds are sub-divided into various categories. They include personal sources, borrowing from family and friends, retained profits and shared capital invested by the entrepreneur.

The personal sources of funds represent the immediate source for the entrepreneur and they are often readily available. Darkwah et al (2013) notes that this source is the most important of all sources particularly for very small enterprises. Most SME start-ups are triggered by the change in the personal financial circumstances of the entrepreneur. Where there is an improvement in the personal financial status, the entrepreneur makes changes in order to improve upon the operationalization of the firm.

Family and friends who are well to do have been supportive of many business ideas and represent the main source of funds for some SME operators. One advantage of this type of source is that, money borrowed are often more or less interest-free and they come with more flexible repayment terms.

Retained profits and shared capital represent other sources of funds for some SME operators. Retained profits refer to the generated cash when a business trades profitably while the share capital represents the contribution of the shareholders to the capital in the firm in the form of shares.

\subsubsection{External Sources of Funds}

The main external source of funds for SME operators include the banks loans, Bank overdrafts, Business Angels and Venture Capital Fund.

The bank loans represents a longer term source of financing to SMEs with the bank spelling out the terms and conditions which usually include the period over which the loan is provided, the interest rate at which it is provided and the terms of repayments. This source is less flexible compared with borrowing from family and friends as the banks usually demand some security for the loan. SMEs operators can also go in for bank overdrafts which has a shorter term kind of finance.

Business angels on the other hand represent external investors in the start-up of SMEs. They are individuals who have the desire and the means to invest in small businesses (Stokes \& Wilson, 2006). The business angels provide the money in addition to the expertise and contacts that they make available to the SMEs. 
Unlike business angels, venture capitalist invest in businesses that have established themselves and would rarely invest in genuine small businesses or start-ups (Darkwah et al 2013). Venture capital represents a share investment that is from funds that are managed by professional investors.

\subsection{Challenges Faced by SMEs in Ghana}

In spite of the contributions of SMEs to the Ghanaian economy, the impacts are not much felt as these SMEs are often entangled in a myriad of challenges. These challenges hamper the possibility of these enterprises from operating at their optimal levels. Some of these challenges include the following:

\subsubsection{Difficulty in Accessing Credit from Banks or Other Financial Institutions}

The survival of every SME, thrives on access to funds for its operations. Where access to funds becomes limited, the functioning of SMEs suffer a blow. According to Fabunmi (2004), this challenge manifests in financial institutions denying SMEs access to credit mostly because of poor and inadequate documentation of business proposals, lack of appropriate and adequate collateral, high cost of administrative and management of small loans as well as high interest rates (Fabunmi 2004:32). The situation is not different in Ghana as most SMEs find it extremely difficult to access funds from banks and other financial institutions mainly due to the aforementioned problems. In a very in-depth survey, Ackah and Vuvor (2011) expanded on the dimension of these challenge. They note that this challenge manifest in the fact that these SMEs are faced with high interest rates and short repayment periods. These challenges tied to the issue of collateral makes it extremely difficult for most of the SMEs to meet the requirements that most of these financial institutions (banks and non-bank institutions) require.

\subsubsection{Lack of Appropriate Managerial and Entrepreneurial Skills}

Majority of SME operators in Ghana lack the requisite expertise in terms of managerial and entrepreneurial skills which are prerequisites for a successful business performance. With this state of affairs, the SMEs operators are unable to prepare strategic plans, business plans, succession plans, effective organizational set-up and transparent operational system (Tijani-Alawe, 2004:14). Consequently, these SMEs resort to the purchase of crude and inefficient equipment that results in very low levels of production and substandard products.

\subsubsection{Market Constraints}

Small scale businesses are faced with stiff competitions from similar establishments both in the local and foreign domains in the production of similar good and/or services. They are often overpowered by the competition by foreigners who use advanced technology to produce close substitutes and offer them at relatively lower prices compared to the market prices of the local SMEs products. This results in a situation where the consumers fall for those produced by foreigners. This lack of patronage of locally produced goods by the general public can lead to the collapse of most of these SMEs.

\subsubsection{Input Constraints}

The availability of inputs and the appropriate blend of these inputs dictates the success of SMEs. Factor availability and costs are often the most common constraints to most SMEs. These constraints are in the form of their access, their availability and whether they are based primarily on imported or domestic inputs (Parker et al, 1995). In the Ghanaian context, most SMEs lack the raw materials needed for their appropriate functioning (Parker et al, 1995).

\subsubsection{Institutional Constraints}

The bureaucratic nature of institutions that SMEs have to deal with often does not also help matters. The bureaucracy manifests in lengthy and prolonged registration procedures. In Ghana, the bureaucratic procedure involved in registering and starting a business is often a challenge to many SME operators.

\subsubsection{Lack of Appropriate Technology}

Technology is a crucial tool around which the improvement of lives and business revolve (Kotler \& Keller, 2006). However technological advancements are rather a challenge to most SMEs. Even with the advances in technology, many SMEs are still stuck to the crude methods of operations. In Ghana, technological advancement has not been taken advantage of, hence many SMEs both in the rural and urban centers still do not benefit from it. The lack of utilization of available technology is aggravated by the limited power supply particularly to the rural areas who do not have for example internet connectivity and access to information networks. According to Duan et al (2002) the lack of ICT knowledge and skills continue to pose a major challenge to many of these SMEs.

\section{Research Methodology}

\subsection{Research Paradigms}

Research paradigm describes the arrangement of conditions for gathering and analysis of data in a manner that aims to combine relevance to the research purpose with economy in procedure (Kothari, 2004). The two main paradigms include the positivism (quantitative) and phenomenology (qualitative).

The qualitative research approach (phenomenology) refers to the approach that is adopted when we describing attitudes, behaviours and experiences of interview subjects. This is often done through the use of methods such as 
interviews and focus groups. The aim of such an approach is to seek an extensive and in-depth opinion from the research participants (Dawson, 2007).

Quantitative research (Positivism) is a research approach that generates statistics usually through the use of large-scale study. It often uses methods such as questionnaire and structured interview (Dawson, 2007). In other words, the quantitative research involves the use of numbers, measurements, experiments and numerical relations between variables under study whilst qualitative research tends to focus on understanding and meaning of variables through verbal narratives (Cochran, 1963).

This study adopted a mixed approach where both qualitative and quantitative variables were considered. The quantitative approach was applied in seeking information from the SME operators in the Tamale Metropolis. The qualitative paradigm was applied in seeking the relevant information from the National Board for Small Scale Industry (NBSSI). This was necessary as the researcher wanted to get in-depth and extensive information from the research participants.

\subsection{Purpose of the Study}

Research is normally carried out in order to serve many purposes. Basically, there are three most useful purposes in every research exercise. They are exploratory, descriptive and explanatory. Although a particular study can have more than one of these purposes, however, examining them separately may have implications for other aspects of the research design.

Exploratory research can be described as the initial research into a hypothetical or even theoretical idea. This is where a researcher comes out with an idea or has observed something and seeks to have a deeper understanding about it. An exploratory research project is an attempt to lay the footwork that will lead to future studies, or to determine whether what is being observed might be explained by the existing theory. Most often, exploratory research provides the initial groundwork for further investigations (Babie, 2005).

Immediately the groundwork is established, the newly explored field needs more information. Therefore, the next step is descriptive research, defined as attempts to explore and explain while providing additional information about a research topic. Thus, descriptive research involves a field survey in which the researcher goes to the population of interest to elicit information about the problem under study. A descriptive research design can be described as the systematic and empirical inquiry into an issue in which the researcher does not have a direct control of the independent variable for their manifestation might have already occurred or because they naturally cannot be influenced (Mugenda \& Mugenda, 2003). Descriptive research design allows the researcher to explore further and to seek explanations from the interview subjects. Descriptive research designs also helps to provide appropriate answers to queries of why, how and when; questions that are critical to the heart of the researcher (Babie, 2005).

From the above discussions it is realized that whenever we want to explore something new, or get more insight into a particular phenomenon, exploratory research is used. This is followed by a descriptive research to improve our knowledge of the phenomenon. Then the last thing we do is to make efforts to describe the phenomenon.

Thus explanatory research is described as an attempt to relate ideas to cause and effect, implying researchers want to explain what's going on. Explanatory research examines how things come together and interact. This research occurs only when there is enough understanding to begin with in order to predict what will come next with some precision (Babie, 2005).

The study adopted a descriptive research design to assess the factors influencing the performance of SMEs in the Tamale Metropolis. The study adopted descriptive survey for the data collection in order to answer the research questions because the researcher did not have full control over the factors that might influence the behaviour and performance of subjects under study thereby reporting the findings of the study as they are.

\subsection{Sources of Data for the Study}

Data simply refers to a representation of facts, concepts or instructions in a formalised manner suitable for communication, interpretation, or processing by humans or by automatic means (Checkland \& Howlwell, 1998). The data for the study were obtained from both primary and secondary sources. Primary data refer to data which are collected afresh and for the first time, and thus happens to be original in nature. Primary data mainly come from direct observation of events, manipulation of variables, contrivance of research situations including performance of experiments and responses to questionnaires. Such data are published by authorities which are themselves responsible for their collection (IDL, 2008; Cornelia, 2012).

Secondary data on the other hand, refers to data which, though relevant for the current study, were obtained primarily from another study. Thus, Secondary data are information which have previously been collected by some organization to satisfy its own need but it is being used by the department under reference for a completely different purpose. Data from these sources were not original to the researcher; they were gathered by other people (IDL, 2008; Cornelia, 2012).

In this research, the primary sources of data included data the researcher obtained from the field work. The primary sources of data were obtained mainly from the analysis of the views expressed by the respondents selected for the study and this type of data constituted the main source of data the researcher used in the study.

The researcher also considered data from secondary sources to guide the overall objective of the study. The secondary data or data from archival sources were obtained from the National Board for Small Scale Industries' (NBSSI) documents and information from the Registrar General's Department in the Metropolis. The secondary data was useful in providing bibliographical information on relevant sources of data to complement the fresh knowledge that the primary 
source of data provided. However, the data was cross-checked by the researcher to verify their authenticity and relevance before using them in the research. The researcher also subjected the data obtained from the secondary sources to critical analysis by taking into consideration their sources, ages and their relevance to the topic under study. This was done to ensure that only relevant and authentic data were considered in the research.

\subsection{Data Collection Methods}

Research instruments involve the use of clear guides for obtaining information from research participants. According to Pope (2000), research instruments refer to tools such as questionnaire, interview guides, observation and other forms of guides the researcher uses to elicit information from elements under investigation. The two main tools adopted for the study were questionnaire and interviews.

\subsubsection{Questionnaire Administration}

This study adopted questionnaire as the main research instrument. Questionnaires are formal questions written down for research participants to provide answers on for the ultimate aim of providing formation that would be helpful to the researcher to make informed judgments (Barnett, 2002). The use of questionnaire is appropriate because they are capable of collecting information that are not directly observable as they enquire about the respondents' feeling, motivation and experiences (Gall \& Borg, 1996). The researcher also made use of an interview guide to elicit in-depth information from the respondents especially the illiterate SME operators, though on a limited scale.

The questionnaire was designed to elicit respondents' views on the factors influencing the performance of SMEs in the Tamale Metropolis.

The questions used in the questionnaire were semi-structured and administered to 250 respondents selected for the study. Both closed-ended and opened-ended questions were used to obtain information from the respondents. As a way of minimising researcher bias, the open-ended questions were provided to give respondents the opportunity to explain so as to provide further details on variables under consideration (Babbie, 2005). On the other hand, the closedended questions offered respondents the needed time and space to provide appropriate answers to the questions by choosing from list of possible options made available to them in the questionnaire. The researcher however made sure that most of the questions were closed-ended. This was done to ensure that respondents' views were guided within the thematic areas dictated by the research objectives in order to prevent too much digression.

\subsubsection{Interview}

An interview is a data collection encounter in which one person (an interviewer) asks questions of another (an interviewee) with a view to eliciting relevant data for the study. It is done between the interviewer and the interviewee on one-on-one basis. Basically, there are two basic types of interviews, structured and unstructured. In a structured interview, standardized questions are asked in a predetermined manner, with relatively little freedom given to the interviewers. With regard to an unstructured interview, broad questions are asked, which allows interviewers freedom in determining what further questions to ask to obtain the required data (Tayie, 2005; Dawson, 2007). Structured questions help the interviewer to remain focused and save time throughout the process of the interview. Interviews have an added advantage of increasing the response rate and also help the researcher to probe further for more details (Babie, 2005). In this study, the researcher interviewed the management of National Board for Small Scale Industries (NBSSI). The NBSSI is a formal body that regulates the operations of SMEs in the Tamale metropolis. The interview was therefore necessary in order to ascertain the level of involvement of the NBSSI in the regulation of SMEs in the metropolis. The interview lasted for 30 minutes. All of these was done in the premises of the NBSSI in the Tamale Metropolis. The researcher ensured that all the relevant responses were written down in a diary for purposes of referencing.

\subsection{Sampling Procedure}

This unit discusses the population and sample as well as the sampling technique used for the study.

\subsubsection{Population and Sample}

Population refers to the total number of people the researcher wishes to obtain information from while sample represents a fraction or segment of the total population whose characteristics is used to represent the entire population (Babie, 2005). The issue of sample arises because, in some situations it is not easy to study the entire population. To truly represent the population, a sample should be randomly selected and adequately large. The process of selecting a number of study elements from a predefined study population is called sampling (Tayie, 2005; Dawson, 2007). Tamale Metropolis has a total of 1,927 number of registered SMEs of various categories (RGD, 2016). The target population for the study included both registered and non-registered SMEs operating in the Metropolis. The researcher considered both the registered and the unregistered SMEs on the grounds that each of them may have experiences which are unique to it and could be very relevant to the study (Dawson, 2007).

Target population involves the total number of all units from which the researcher selects the sample in the study area for investigation (Bryman, 1989). Due to logistical constraints, a section of the population is often selected and studied as a reflection of the entire population (Obeng, 2003). A sample is a portion of the total population that the researcher considers to be a true representation of the entire population (Barnett, 2002). If properly selected and studied, the outcome of the study can be generalized to be a true reflection of the entire elements in the study area (Yin, 1994).

The study considered all the categories of registered SME operations including Trade and Commerce; Services; light manufacturing, construction/oil and gas, Agro business and others. 
The distribution of the registered SMEs in the metropolis is as shown in Table 3below:

\begin{tabular}{|c|c|}
\hline Category & Frequency \\
\hline Trade and commerce & 297 \\
\hline Services & 802 \\
\hline Construction/Oil and Gas & 104 \\
\hline Manufacturing & 6 \\
\hline Agro-business & 53 \\
\hline Others & 665 \\
\hline Total & 1927 \\
\hline
\end{tabular}

Table 3: Target Population

Source: Registrar General's Department (2016)

\subsection{Sampling Technique}

In selecting the sample to be included in the study, the researcher adopted both the probability and nonprobability sampling techniques.

The study considered a sample size of 235 participants consisting of both registered and unregistered SMEs operating various categories of businesses in the Tamale Metropolis.

Particularly, the purposive (judgment) sampling technique which is a non-probability sampling technique was used to select a total of 50 respondents from unregistered SMEs category. Judgment sampling is also called purposive sampling. Under this sampling procedure, a researcher deliberately or purposively draws a sample from the population which he thinks is a representative of the entire population. A purposive sample is chosen with the knowledge that it is not representative of the general population, rather it attempts to represent a specific portion of the population (Babie, 2005; Tayie, 2005).

With regard to the selection of registered SMEs to be included in the study, the cluster sampling technique, which is a probability sampling technique was adopted in which groups or categories (clusters) of the population units were selected at random and all or some of the units in the chosen clusters were studied.

For the exact individuals to participate in the study, the researcher used systematic sampling technique to select a total of 185 respondents from the population of 1,927 registered SMEs in the Metropolis. Systematic sampling is a probability sampling technique in which every kth element in a list is selected for inclusion in the sample. The researcher preferred this sampling technique to others because of its simplicity, accuracy, operational convenience and also it spreads the sample over the target population (Babbie, 2005).With this sampling technique too, every sampling frame (cluster) has equal chance of being included in the sample.

This was done using a sampling interval of $10\left(\frac{1927}{185}\right)$. With this sampling interval, the list of the respondents was counted in a non-replacement form and the 10th element of every element counted was selected for the study starting from the first element when counting. The first element was determined through a lottery method from the list of the target population. This was made possible by drawing the list of all registered SMEs from the ICT Unit of the Registrar General's Department in the Tamale Metropolis.

The proportional sample allocation to each sampling frame (cluster) is shown below and the results depicted in Table 4.

Proportional sample allocation $=\mathrm{n}^{*} \frac{\mathrm{S}}{\mathrm{N}}$

Where $\mathrm{n}=$ sample size for registered SMEs

Where $\mathrm{n}=$ sample size for registered

$\mathrm{S}=$ total number of elements in each cluster

$\mathrm{N}=$ Total population of registered SMEs. But $\mathrm{N}=1,927$ and $\mathrm{n}=185$

For trade and Commerce $=\mathrm{n}_{1} * \frac{\mathrm{S} 1}{N}=185 * \frac{297}{1927}=28$

For services $=\mathrm{n}_{2} * \frac{\mathrm{S} 2}{\mathrm{~N}}=185 * \frac{802}{1927}=77$

For construction/Oil and Gas etc. $=\mathrm{n}_{3} * \frac{\mathrm{S} 3}{\mathrm{~N}}=185 * \frac{104}{1927}=10$

Manufacturing $=\mathrm{n}_{4} * \frac{\mathrm{S} 4}{N}=185 * \frac{6}{1927}=1$

For Agro business $=\mathrm{n}_{5} * \frac{\mathrm{S} 5}{N}=185 * \frac{53}{1927}=5$

For others $=\mathrm{n}_{6} * \frac{\mathrm{S} 6}{N}=185 * \frac{665}{1927}=64$

Total number of elements $=28+77+10+1+5+64=185$

Sample fraction $=\frac{1927}{200}=10$ 


\begin{tabular}{|c|c|c|}
\hline Category & Sample & Percentage \\
\hline Trade and commerce & 28 & 15.1 \\
\hline Service & 77 & 41.6 \\
\hline Construction/Oil and Gas & 10 & 5.5 \\
\hline Light manufacturing & 1 & 0.5 \\
\hline Agro business & 5 & 2.7 \\
\hline Others & 64 & 34.6 \\
\hline Total & 185 & 100 \\
\hline
\end{tabular}

Table 4: The Number of Respondents under the Various SME Business Categories

Source: Author, 2016

\subsection{Sample Size Determination}

The sample size used for this research will comprise both registered and unregistered SMEs operating various businesses in the Tamale Metropolis. As regards the number of unregistered SMEs to be considered for the study, the researcher chose a convenient sample size of 50 participants. The reason is that the total population of SMEs within this category from which the sample could be scientifically determined was unknown. Also, the researcher could not exactly locate these category of SMEs in the Metropolis let alone to determine the nature of their businesses. Therefore, the researcher by his own judgment will interview any participant within this category as and when they are available. However, the researcher was mindful of the need to ensure accuracy and relevance in terms of the data to be collected as dictated by the objectives of the study.

With regard to the sample size for the registered SMEs category, the researcher used the Yamane (1967) simplified formula for determining sample size as shown below:

$\mathrm{n}=\frac{N}{1+N(e)^{2}}$

Where

$\mathrm{n}$ - is the sample size,

$\mathrm{N}$ - is the population size, and

e - is the level of precision

With confidence level of $95 \%$ and $\mathrm{p}$ value of 0.05 .

But $\mathrm{N}=1927$ and $\mathrm{e}=7 \%(0.07)$

Thus $\mathrm{n}=1927 /\left(1+1927\left(0.07^{2}\right)\right)$

$\mathrm{n}=1927 /(1+1927(0.0049))$

$\mathrm{n}=1927 /(1+9.4423)$

$\mathrm{n}=1927 /$

$\mathrm{n}=184.5$

$\mathrm{n}=185$

Hence the sample size of 185 respondents from registered SMEs category selected for the study.

\subsection{Data Analysis and Presentation}

Data obtained from the field was cross-checked and edited. It was also coded and processed using software such as SPSS and Excel. The data was then analysed and the results presented in the form of Tables and Figures to facilitate easy understanding and interpretation. The following summarizes the data analysis and presentation process.

In the first place, when the data arrives from the field, it is edited. The researcher does this by reading through the administered questionnaires and interview guide to make corrections and to also offer grammatical corrections. This was done so as to ensure the overall accuracy and uniformity in the interpretations.

The next task for the researcher after the data is edited is to code the data. Coding is the means by which the researcher transforms the data contained in the administered questionnaire into a structure that is compatible for computer analysis. This is where responses are classified into categories that are meaningful to bring out patterns as the basis for analysis.

Immediately the field data are coded then data entry follows. By data entry, it is meant transferring the coded data into the computer using SPSS for purposes of analysis.

Finally, the researcher presents the data in the form of statistical variables such as percentages, averages and frequency distributions. Pie charts, bar charts, tables and other frequency distribution variables are also ways by which data is presented.

\section{Data Presentation and Discussions}

\subsection{Demographic Data of Respondents}

This section of the study sought to analyse the personal data of the respondents. Among the demographic characteristics of the respondents the study considered include; sex, age, educational level, marital status as well as number of years the person has operated his/her business. 


\subsubsection{Gender of the Respondents}

In order to obtain in-depth information on the demographic data of the respondents selected for the study, they were made to indicate their sex to help inform the study. Analysis of the field data indicated that majority of the respondents were males as illustrated on the Table 5 below. From the Table, it was realised that 138 of the respondents indicated that they were males whilst the remaining 97 respondents indicated that they were females, representing $59 \%$ and $41 \%$ respectively. The study points to a gender imbalance in the administration of the questionnaires, implying that more males participated in the study than females.

\begin{tabular}{|c|c|c|}
\hline Gender & Frequency & Percent \\
\hline Male & 138 & 59 \\
\hline Female & 97 & 41 \\
\hline Total & 235 & 100 \\
\hline
\end{tabular}

Table 5: Gender of the Respondents

Source: Field Data, 2016

\subsubsection{Age of Respondents}

Another key demographic characteristic of the respondents the study considered was age. This was to help inform the researcher on the extent to which the respondents would appreciate the concept of entrepreneurship and small scale business operations in the Tamale Metropolis.

Age is an important factor in entrepreneurship as it provides credibility in business relations and also it determines an individual's propensity to take risk.

Owing to this, respondents were asked to indicate their ages and the results of the findings are presented in Table 4.1.2 below: From the Table, it can be seen that $7.7 \%$ of the respondents was aged between $18-25$ years while $22.6 \%$ fell within 25-30 age bracket. Also, $42.1 \%$ of the respondents had their ages falling within the 31-40 age groups. Similarly, $22.6 \%$ were within $41-50$ years whilst $5.1 \%$ of the respondents indicated they were above 50 years. The findings indicate that most of the SME operators in the Tamale Metropolis were within the 31-40 age bracket. This implies most of the respondents are matured enough to make independent decisions especially in relation to trade and commerce.

\begin{tabular}{|c|c|c|}
\hline Age & Frequency & Percent \\
\hline $18-25$ years & 18 & 7.7 \\
\hline $26-30$ years & 53 & 22.6 \\
\hline $31-40$ & 99 & 42.1 \\
\hline 41-50 years & 53 & 22.6 \\
\hline 50 years + & 12 & 5.1 \\
\hline Total & 235 & 100.0 \\
\hline
\end{tabular}

Table 6: Age Distribution of Respondents

Source: Field Data, 2016

\subsubsection{Educational Level of Respondents}

Another equally important demographic data the study considered was educational level of respondents. The researcher believes that peoples' experiences and learning would guide them in their conception of issues of entrepreneurship and small scale business operations in the Metropolis. Thus, the respondents were asked to indicate their levels of education and the results of the findings are presented in Figure 4.1.3 below. It was realised in Figure 4.1.3 that $25.1 \%$ of the respondents had no formal education whilst $17 \%$ of the respondents had basic education. , whereas $11.1 \%$ of the respondents had vocational and technical education. It was only $18.7 \%$ and $5.1 \%$ of the sampled respondents who had tertiary and post-graduate education respectively. The findings indicate a high proportion of illiterates among SME operators in the Tamale Metropolis. This situation is not surprising as a number of studies points to a high preponderance of demand for white-colour jobs among the literate population in Ghana.

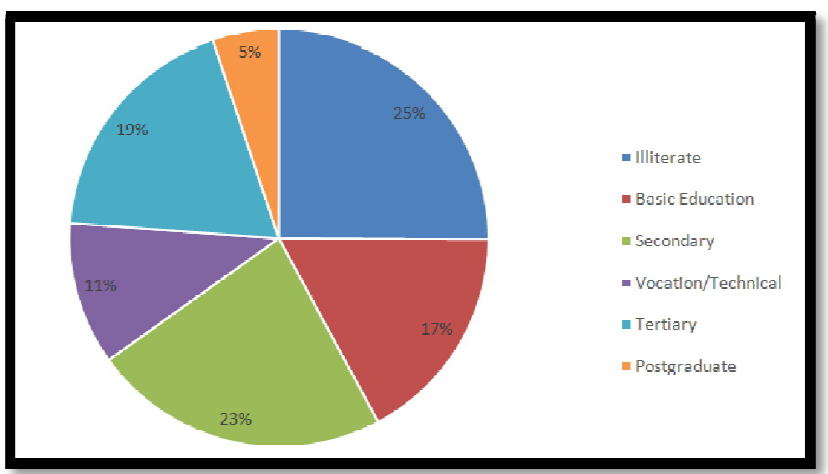

Figure 1: Educational Level Respondents Source: Field Data, 2016 


\subsubsection{Marital Status of Respondents}

Also considered under the demographic characteristics of respondents included marital status. Sampled respondents were made to indicate their marital status and the results of the findings presented in Figure 2 below. The Figure revealed that $79.1 \%$ of the respondents indicated that they were married whilst $13.6 \%$ of the sampled respondents indicated they were single. Also, $4.7 \%$ of the respondents were people who had been divorced, with $2.6 \%$ of the respondents indicating that they were widows. The findings above indicate that majority of the SME operators in the Tamale metropolis were married. This development is good for small business ownership as single people are less likely to be owner-managers or self-employed than those who are married as postulated by Stokes and Wilson (2006).

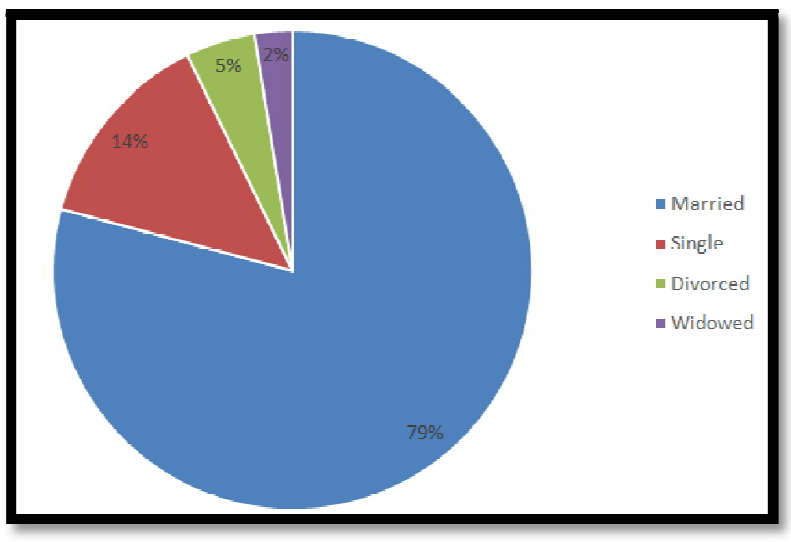

Figure 2: Marital Status of Respondents Source: Field Data, 2016

\subsubsection{Number of Years of Operation}

The final item the study considered under the demographic characteristics of the respondents was the number of years the SME operator had been running the business in the Tamale Metropolis. The results of the findings are presented in Figure 3 below. From the Figure, it can be seen that $11.5 \%$ of the respondents had been operating in the Metropolis for at least $0-5$ years whilst $28.1 \%$ operated in the Metropolis for $2-5$ years. The Figure also indicated that only $33.6 \%$ of sampled respondents had been in business for 6-10 years, whereas $21.7 \%$ and $5.1 \%$ had operated in the Metropolis for 11-20 and over 21 years respectively. The findings indicate that the businesses have been in operation long enough to understand the issues sought by the researcher

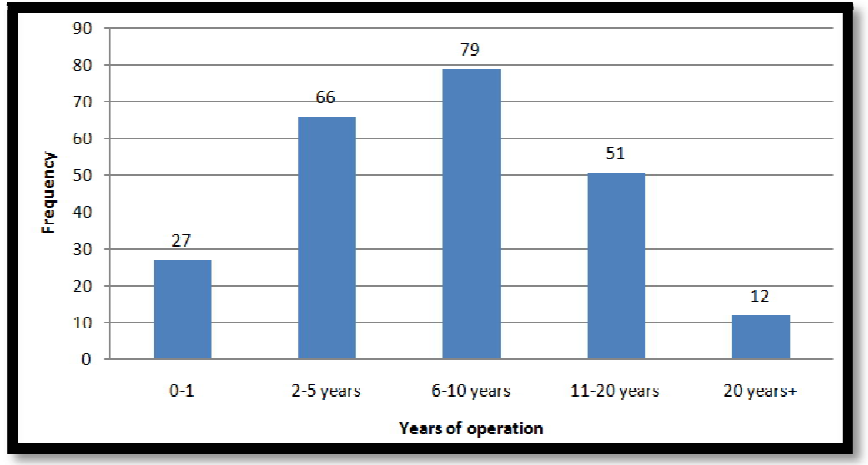

Figure 3: Number of Years of Operation Source: Field Data, 2016

\subsection{Business Operation- General Characteristics and Experience}

This section of the study sought to elicit information on the basic traits that determine the nature of SMEs and their operators in the Tamale Metropolis. The researcher therefore interrogated the respondents on a broad range of behavioural characteristics of SME operators aimed at unearthing the very factors that define the nature of their operations and which consequently set -them apart from the larger business units.

\subsubsection{Reasons for Starting a Business}

The study first considered the reason why the SME operators would prefer to start their own business. The respondents were asked to indicate the reason why they would prefer to start their own business. This particular question was meant to unearth the motivation behind the formation of businesses in the Tamale Metropolis. The views of the respondents with respect to this particular issue were analysed and the results presented in Table 7 below. It was realised in the Table that $4 \%$ of the respondents indicated they were in business because it is a family tradition whilst $20 \%$ of the respondents indicated that they were operating the small business as a result of the smaller investment required. Also, $50 \%$ of the respondents said they started their own businesses because it was a source of employment to them, whereas $9 \%$ indicated they had no other alternative source of income, only $17 \%$ of the respondents business because it brings more 
income. The findings establish a high proportion of respondents establishing businesses to serve as a source of employment. This finding goes to confirm the findings of Ayyagari et al. (2011) that SMEs are responsible for 60\% of private sector employment.

\begin{tabular}{|c|c|c|}
\hline Reason & Frequency & Percentage \\
\hline Family tradition & 9 & 4 \\
\hline Small investment is required & 47 & 20 \\
\hline To be Self-employed & 118 & 50 \\
\hline No other alternative for incomes & 21 & 9 \\
\hline Brings high income & 40 & 17 \\
\hline Total & 235 & 100 \\
\hline
\end{tabular}

Table 7: Reason for Starting a Business

Source: Field Data, 2016

\subsubsection{Skills Acquisition for Running the Enterprise}

Another key entrepreneurial characteristics that the study considered was mode of skill acquisition for the running of the business. The researcher consider this important because the success of a business to a large extent depends on the competence and experience of the entrepreneur. Thus, the respondents were made to indicate the source of skills for running their businesses. The views of the respondents were analysed and the results presented in Figure 4.2.2 below. From the Figure, it can be seen that $41 \%$ of the respondents indicated they acquired their business management skills through formal training. It was $51 \%$ of the respondents who said they acquired the needed skills for managing their businesses through past experience, only $8 \%$ of the respondents indicated they acquired the skills through their family members. The results indicate majority of the respondents acquiring their business management skills from previous businesses or mentors. This is not surprising as the study revealed a larger proportion of the SME operators in the Tamale Metropolis having no formal education where they would be thought formally, business management techniques.

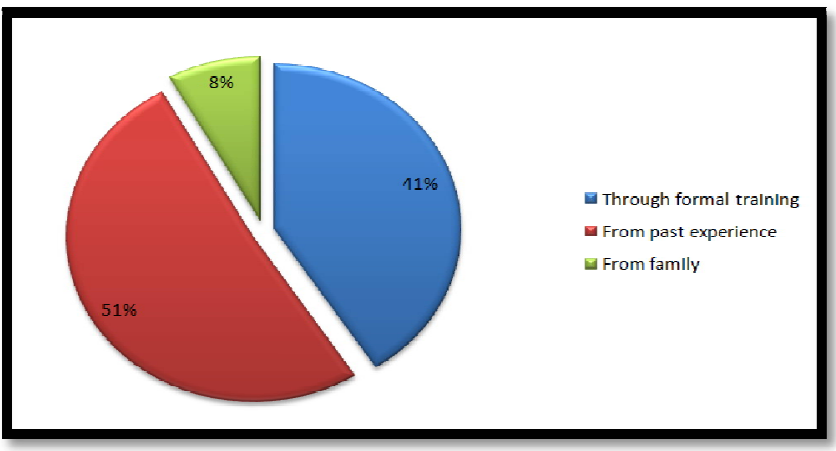

Figure 4: Ways of Acquiring Entrepreneurial Skills Source: Field Data, 2016

\subsubsection{Entrepreneurial Background}

This questionnaire item sought to elicit respondents' views on whether any member of the entrepreneur's family had ever run a business before. This was meant to uncover the entrepreneurial background of the respondents in the study area. To this end, the respondents were asked to indicate whether or not any of the family relations had been entrepreneurs before. The researcher collected their views, analysed them and the results of the analysis presented in Figure 5 below. From the Figure, 63\% of the respondents indicated that a family had been an entrepreneur before, only $37 \%$ of the respondents had a contrary view. The findings indicate most of the respondents have had a relative owning a business or managing a business before. The implication is that those whose relations have been running businesses are likely to have high inclination to start businesses those whose relations have never run any business before.

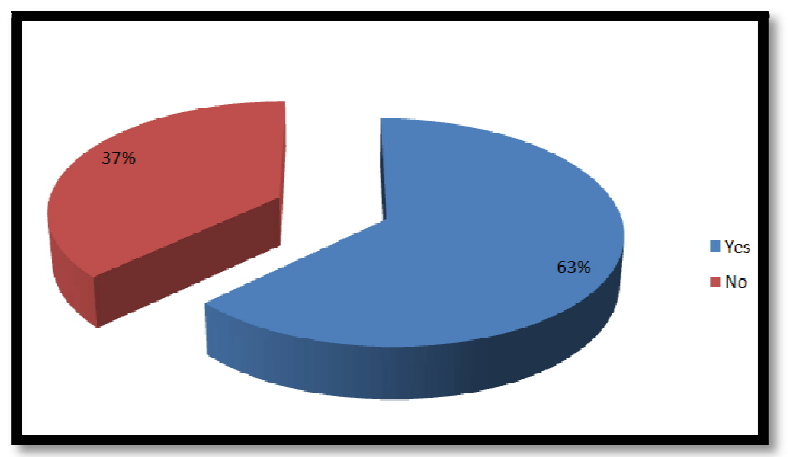

Figure 5: Is There Any One in Your Family Who Was an Entrepreneur Source: Field Data, 2016 


\subsubsection{Number of Employees of the Enterprise}

The study further looked at the number of employees of the enterprise operating in the Tamale Metropolis. This was meant to figure out the real categories of businesses operating in the Tamale Metropolis. The views of the respondents were analysed and the results of the analysis presented in Figure 2 below. From the Figure, it was revealed that an overwhelmingly $77 \%$ of the respondents indicated they had employee size falling within $1-10$ whereas $20 \%$ of the indicated they have employee size falling within 11-30. A woefully $3 \%$ of the sampled respondents interviewed said their total of employees was falling between 31-40 employees. The above findings indicate most of the businesses in Tamale Metropolis are small scaled businesses of less than 10 employees per GSS classification of SMEs. Had the researcher considered the classification of enterprises by EC, the same finding would have indicated prevalence of micro enterprises in the Tamale Metropolis.

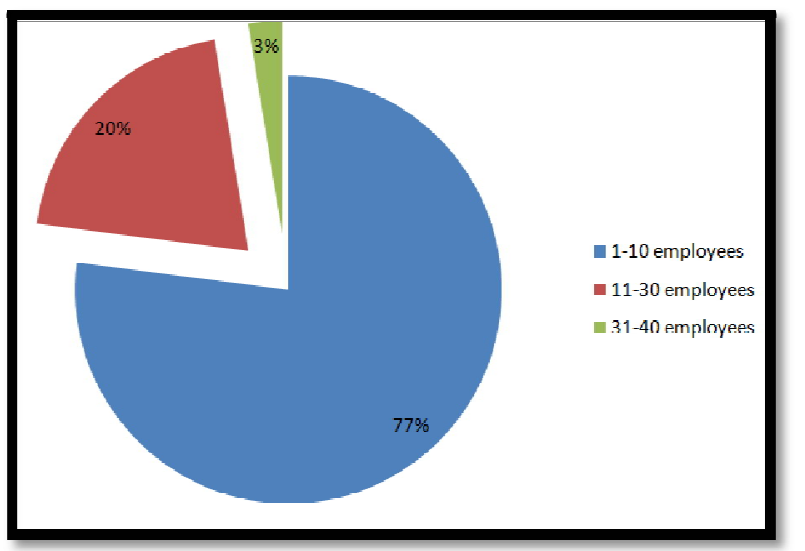

Figure 6: Number of Employees of the Enterprise Source: Field Data, 2016

\subsubsection{Types of Records Kept for Business}

The final item that the study considered under the entrepreneurial characteristics was the type of records kept for the business transactions. Records keeping is an essential component for a successful business operations. With regard to this questionnaire item, respondents were made to indicate the type of business records they keep for their day-to-day business transactions. The views of the respondents were analysed and the results presented in Table 8 below. From the Table it was revealed that $17 \%$ of the respondents indicated they kept records for inventory movement whilst $20 \%$ indicated that they kept sales records. Also, $28 \%$ and $6 \%$ of the sampled respondents indicated that they kept records for Cash and Debtors respectively. It was further revealed that $7 \%$ of the respondents indicated they kept records for customers whereas $8 \%$ indicated they kept records for Suppliers. It was only $14 \%$ of the respondents who indicated they did not keep any record regarding their day-to-day business transactions. The findings show $80 \%$ of the respondents keeping one record or the other, with majority of the respondents keeping records of cash and sales. The study showed only a few number of the respondents failing to maintain any structured records of their business transactions

\begin{tabular}{|c|c|c|c|}
\hline Records kept & & Frequency & Percent \\
\hline Inventory records & & 40 & 17 \\
\hline Sales records & & 48 & 21 \\
\hline Cash book records & & 66 & 28 \\
\hline Customer records & & 24 & 10 \\
\hline Supplier records & & 24 & 10 \\
\hline None & & 33 & 14 \\
\hline Total & $\mathbf{2 3 5}$ & $\mathbf{1 0 0}$ \\
\hline
\end{tabular}

Table 8: Type of Records Kept for Business

Source: Field Data, 2016

\subsection{Sources of Funding for Small and Medium and Scale Enterprises}

The success of any business hinges partly on availability of funding. Access to reliable source off funding is a critical requirement for a successful SME operation. This section considers the funding mechanisms for SMEs in the Metropolis by looking at the start-up funding sources, the sources of funding after start up and the common challenges that were faced by SMEs in accessing funds from formal financial institutions.

\subsubsection{Sources of Start-up Funding}

All business plans and intentions are backed by the startup capital to put the ideas into concrete substance. Figure 7 illustrates the funding sources for starting up SMEs in the study area. 


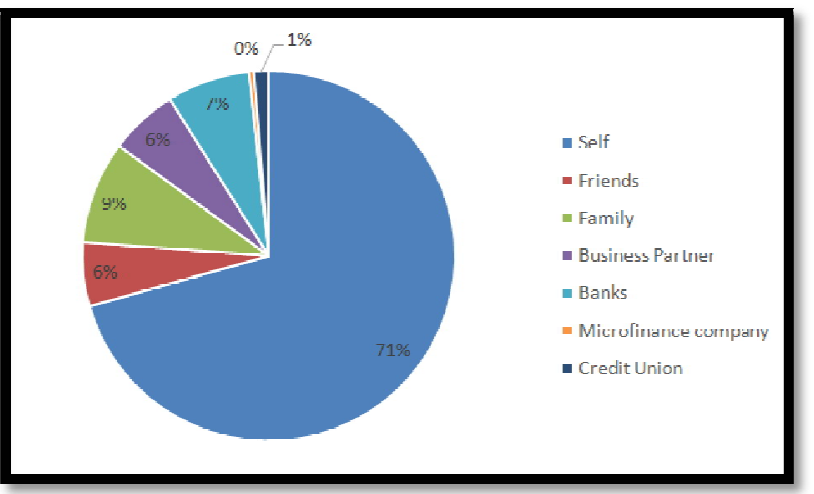

Figure 7: Start-Up Funding Sources for SMEs

Source: Field Data, 2016

The most common source of funding for starting small businesses in the Tamale Metropolis was self-funding. The survey revealed that more than half of all the sampled SME operators self-funded the starting up of their businesses. According to them, they started their businesses from their own personal savings and resources without resort to any form of financial support. The common reason according to the respondents was that the self-funding style was flexible to owners .Respondents also alluded to the fact that self-financing helped them to skip bureaucratic impediments that are associated with other sources of funding such as the banks and other formal financial institutions. This finding reflects Darkwah et al's (2013) assertion of why particularly small businesses tend to self-fund their start-ups. Other sources of funding apart from self-financing the respondents indicated included family and friends and the Commercial Banks. This particular finding was confirmed by the Project Officer of NBSSI when he was asked on the same issue. According to him, SMEs in the metropolis lacked reliable source of funding and this has had a serious implications for the performance of these business entities.

\subsubsection{Sources of Funding after Start-up}

Continuous in-flow of resources after start-up is needed to keep SMEs in operation. Apart from reinvesting profits, SMEs operators in the Metropolis also looked up to some formal financial institutions for assistance. The survey revealed that in spite of the need for financial assistance, 67\% of the SME operators had never sought for any formal financial assistance. Those who have ever sought funding from the formal institution were requested to indicate where they sought their funding. The Figure 8 below illustrates the formal sources of funds for SME operators in the Tamale Metropolis.

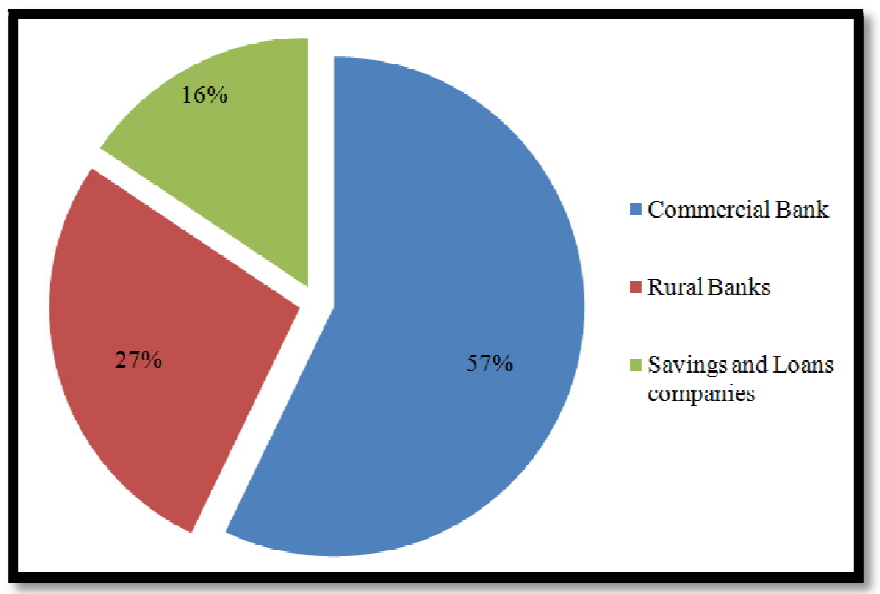

Figure 8: Formal Sources of Funds for SME Operators Source: Field Data, 2016

The Commercial Banks in the metropolis represent the major formal financial institution for majority of SMEs in the metropolis. Other sources included Rural Banks and Savings and Loans companies. The factors that determined the choice of one particular source of funding over the other included mainly recommendations by family and friends and the advertisement coverage of the availability of such funding opportunities for SMEs. By extension, the Commercial Banks performed well in serving many of the SMEs in the Metropolis. SME operators also indicated that funds from formal institutions have often not been adequate for their needs. This has made the SME operators to resort to other funding sources such as micro-finance companies and susu companies.

\subsubsection{Challenges Faced in Accessing Financial Resources}

SME operators who could not access loans from the Commercial Banks attributed a number of reasons for their denial. These are illustrated in the Figure 9 below. 


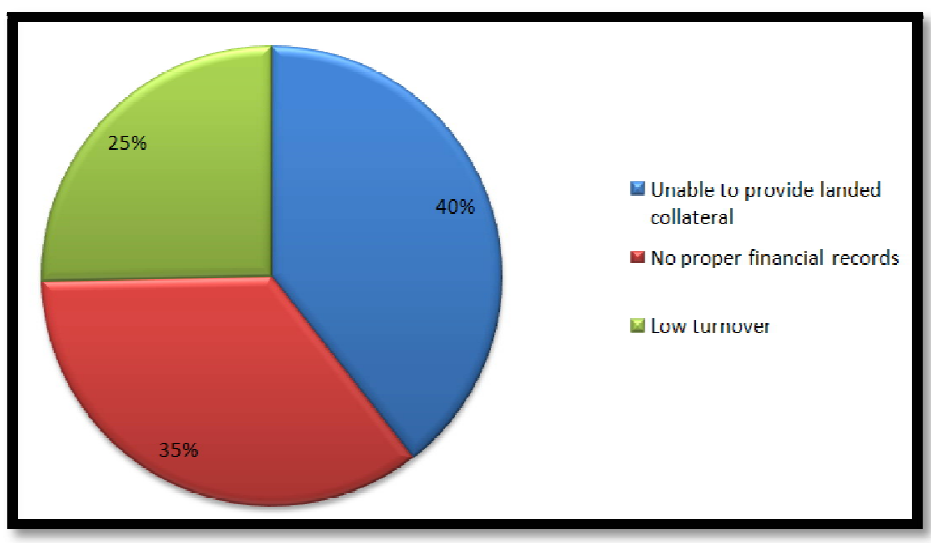

Figure 9: Reasons Cited for Loan Denial

Source: Field Data, 2016

Figure 9 above shows that three main reasons responsible for the denial of credit to SME operators particularly by the Commercial Banks. Among other conditions, $40 \%$ of the SMEs that were denied loans were people who could not provide landed collateral to guarantee their repayment of the loans contracted. Most SMEs operators failed to meet the collateral requirement partly because majority of the SMEs did not have requisite assets demanded by the lending institutions. This confirms previous research such as Frimpong and Antwi's (2014) which found among other conditions that lack of collateral security was the main reason for the loan denial to many infant businesses. Other factors that disqualified SMEs in accessing loan facilities from the Commercial Banks included lack of proper financial records and low turnover.

\subsubsection{Problems Faced in Loan Access}

Access to loan for SMEs that met conditions and criteria set by financial institution was still beset with a number of problems ranging from cumbersome procedures to high interest rates. SMEs operators recounted that these problems associated with the access to loan did not encourage them to seek such financial resources once there were alternatives. Figure 10 illustrates the common problems encountered by SME operators who accessed loan from formal institutions.

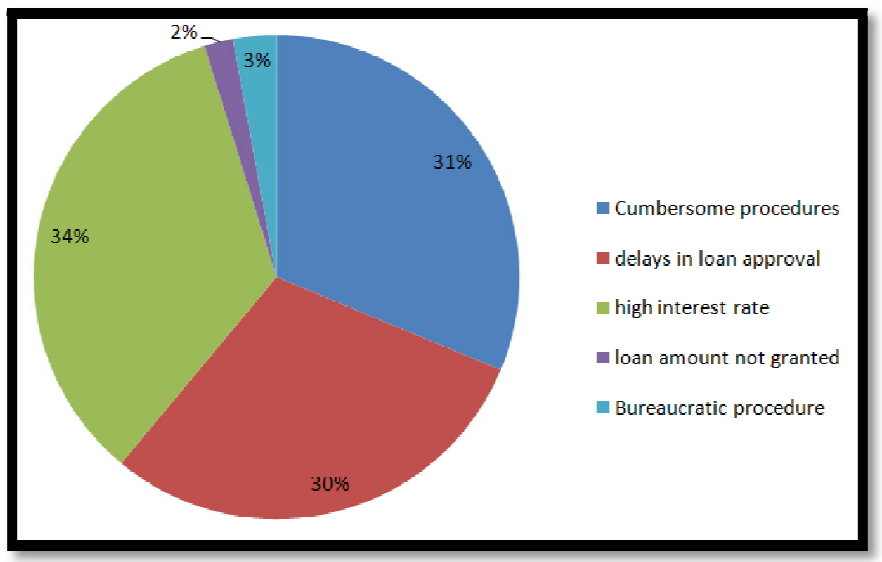

Figure 10: Problems Encountered by SME Operators in Accessing Loans Source: Field Data, 2016

As Figure 10above shows, the common problems for SME operators in accessing loan included cumbersome procedures, delays in loan approval and high interest rates at which the loans must be repaid. These problems, particularly the high interest rates have implications for the long term survival of the small and medium scale enterprises.

\subsection{Challenges Facing Small and Medium Scale Enterprises}

This section discusses the major factors that restrict the small and medium scale enterprises from operating to their optimal levels in the Tamale Metropolis. To this end, respondents were made to express their level of agreement or disagreement to an array of factors which are likely to affect SMEs operations on a Likert-scale. This was to inform the researcher on the extent to which these factors affected the performance of the small and medium scale enterprises in the Tamale metropolis.

\subsubsection{Economic Constraints in Small and Medium Scale Enterprises' Operations}

The study sought the views on some macro- economic fundamentals which might have a toll on the performance of small and medium scale enterprises in the Tamale Metropolis. These economic factors the study considered included interest rates, taxation, and access to inputs. 
On the part the interest charges on loanable funds, the researcher sought the views of respondents on the reasonableness of interest payable on credit extended them. The respondents were asked to express their subjective views on the extent to which they agree or disagree with the reasonableness of the interest charged on the credit facilities extended to them by the financial institutions. It was revealed from the study that $23.3 \%$ of the respondents agreed to the reasonableness of the interest charged, whilst 9.8\% thought otherwise. An overwhelming number of the respondents $(69 \%)$ disagreed to the reasonableness of the interest rates on the credit facilities.

On the issue of taxes payable on goods on goods and service, it was established that over $50 \%$ of the respondents considered the taxes on their goods and services to be astronomical. Majority of them maintained that the level of taxation is adversely affecting their businesses in the sense that it results in price hikes which eventually affects demand for their products.

The study further sought the views of respondents on accessibility to raw materials (inputs) for their business operations. The researcher believed this questionnaire item was necessary as the success or failure of any venture hinges partly on access to raw materials. It was revealed from the study that respondents were not able to access raw materials to effectively run their businesses. Majority of the respondents considered the cost of inputs to be too high for their reach and that if they bought them they would not get any reasonable return on them. The study further revealed that most of the respondents did not find it problematic getting customers for their products. It was agreed by most of the respondents that they had ready market for their products. By virtue of the size and customer base of these SMEs, it is very possible to customize the production of their goods and services to needs and wants of their target market.

\begin{tabular}{|c|c|c|c|c|c|}
\hline Economic Factors & $\begin{array}{c}\text { Strongly } \\
\text { Agree }\end{array}$ & Agree & Undecided & Disagree & $\begin{array}{c}\text { Strongly } \\
\text { Disagree }\end{array}$ \\
\hline $\begin{array}{c}\text { I am satisfied with the financial resources } \\
\text { given by microfinances and other lending } \\
\text { institutions }\end{array}$ & 7 & 18 & 31 & 152 & 27 \\
\hline I have access to raw materials & 22 & 94 & 30 & 82 & 7 \\
& $9 \%$ & $40 \%$ & $13 \%$ & $35 \%$ & $3 \%$ \\
\hline I have access to market for my products & 6 & 114 & 30 & 71 & 14 \\
& $3 \%$ & $48 \%$ & $13 \%$ & $30 \%$ & $6 \%$ \\
\hline Interest rates charged are reasonable & 3 & 47 & 23 & 110 & 52 \\
& $1 \%$ & $20 \%$ & $10 \%$ & $47 \%$ & $22 \%$ \\
\hline Taxes levied on my business are reasonable & 15 & 75 & 17 & 95 & 33 \\
& $6 \%$ & $32 \%$ & $7 \%$ & $40 \%$ & $14 \%$ \\
\hline
\end{tabular}

Table 9: Economic Constraints Faced by SMEs

Source: Field Survey, 2016

\subsubsection{Administrative/ Legal Constraints in SMEs Operations}

The administrative factors that businesses face to a very large extent determine the success or otherwise of such businesses. Table 10 shows the administrative and legal factors that affect SMEs in the Tamale Metropolis.

\begin{tabular}{|c|c|c|c|c|c|}
\hline Administrative and Legal Factors & $\begin{array}{c}\text { Strongly } \\
\text { agree }\end{array}$ & Agree & undecided & Disagree & $\begin{array}{c}\text { Strongly } \\
\text { disagree }\end{array}$ \\
\hline I have access to business assistance and & 5 & 18 & 6 & 95 & 111 \\
support from government & $2 \%$ & $8 \%$ & $3 \%$ & $40 \%$ & $47 \%$ \\
\hline I have no legal, institutional and policy & 29 & 113 & 26 & 42 & 25 \\
constraints & $12 \%$ & $48 \%$ & $11 \%$ & $18 \%$ & $11 \%$ \\
\hline I am a beneficiary of government incentives & 27 & 15 & 12 & 51 & 130 \\
& $12 \%$ & $6 \%$ & $5 \%$ & $22 \%$ & $55 \%$ \\
\hline
\end{tabular}

Table 10: Administrative/ Legal Constraints in SMEs Operations Source: Field Survey, 2016

Results from Table 10 indicate that majority of SME operators in the study area did not have access to business assistance from government. From the Table, 111 (47\%) of the respondents disagreed with the assertion that there were available business assistance and support from government. Related to the above, majority of SMEs did not enjoy incentives from the government. From the table 130 (55\%) of all SME operators strongly disagreed that they had been beneficiaries of any government incentives. However, SME operators generally agreed that there are no legal, institutional and policy constraints that impeded their operation. When the researcher contacted the NBSSI in the metropolis on their view with respect to this, the story was not different because according to them there are instances that monies meant for some particular SME operators, went to other people by virtue of political affiliations. This practice according to them is affecting businesses in the metropolis because those who do not deserve the support by virtue of political considerations are supported at the expense of those who deserve the support. 


\subsubsection{Human Resource Constraints in Small and Medium Scale Enterprises}

Human resource factors are invaluable to every business, irrespective of the size. The human resource management functions of SMEs amongst other things include the hiring of qualified personnel and the ability to reduce or minimize employee turnover. Table 11 presents the human resource factors that affect the SMEs in the Tamale Metropolis.

\begin{tabular}{|c|c|c|c|c|c|}
\hline Human Resource Factors & $\begin{array}{c}\text { Strongly } \\
\text { Agree }\end{array}$ & Agree & Undecided & Disagree & $\begin{array}{c}\text { Strongly } \\
\text { Disagree }\end{array}$ \\
\hline I have no problems hiring personnel & 24 & 101 & 31 & 65 & 14 \\
for my business & $10 \%$ & $43 \%$ & 13 & $28 \%$ & $6 \%$ \\
\hline $\begin{array}{c}\text { There is no frequent employee } \\
\text { turnover in my business }\end{array}$ & 31 & 123 & 19 & 57 & 5 \\
\hline
\end{tabular}

Table 11: Human Resource Constraints in Small and Medium Scale Enterprises Source: Field Survey, 2016

The SMEs have relatively stable human resource system that ensures that the needed personnel were hired and retained for a long period. In assessing the employment difficulties, 43\% of SME operators claimed they did not have problems hiring the needed personnel. This is because of the fact that most of the SMEs operate in the informal sector and access to labour is relatively easy. Also, $52 \%$ of the operators agreed that they were able to retain their working staff for a long period.

\subsubsection{Energy Supply Constraints Faced by SMEs}

Energy supply represents a critical driving force in the day to day operation of SMEs. The Northern Electricity Department of Ghana (NED) is the major supplier of energy for the SMEs in the Tamale Metropolis. The reliability and conditions of service of ECG are critical to the success of SMEs in the metropolis. Table 12 presents the ratings of the effect of energy supply on the success of SMEs in the Tamale Metropolis.

\begin{tabular}{|c|c|c|c|c|c|}
\hline Energy Factors & $\begin{array}{c}\text { Strongly } \\
\text { Agree }\end{array}$ & Agree & Undecided & Disagree & $\begin{array}{c}\text { Strongly } \\
\text { Disagree }\end{array}$ \\
\hline Utility bills for my business are reasonable & 20 & 78 & 2 & 86 & 49 \\
& $9 \%$ & $33 \%$ & $1 \%$ & $36 \%$ & $21 \%$ \\
\hline My business is not affected by energy/power & 47 & 48 & 6 & 60 & 74 \\
fluctuations & $20 \%$ & $20 \%$ & $3 \%$ & $26 \%$ & $31 \%$ \\
\hline
\end{tabular}

Table 12: Energy Supply Constraints Faced by SMEs Source: Field Survey, 2016

Table 12 presents the ratings of energy supply to SMEs in the Tamale Metropolis by examining the measures of reasonable billing systems and reliable power supply.

The Table shows that there were split views in terms of the billing rates imposed on SME operators by the NED. However, majority of the respondents claimed that utility bills were exorbitant for the operators to meet which suffocates the expansion potentials of particularly infant businesses. In this sense, $36 \%$ of the respondents disagreed over the reasonability of utility bills. These SME operators noted that high utility bills increased the cost of production, and with the same level of demand for products/services, the profit-making fortunes of the businesses were equally reduced.

In terms of the reliability of energy supply to SMEs, majority of the SME operators were not satisfied as they noted that they were largely affected by energy fluctuations. The findings of energy supply to SMEs in the Tamale Metropolis substantiate claims by many others on the subject matter and the need for conceited efforts in dealing with erratic power supply situation the better.

\section{Summary of Findings, Conclusion and Recommendations}

\subsection{Summary of Findings}

This section highlights the major findings of the study taking into consideration the objectives the study sets out to achieve.

\subsection{Sources of Funding for Small and Medium Scale Enterprises}

The first major finding of the study was that most of the SMEs in the Tamale Metropolis were funded from personal savings of the owners. The respondents indicated that this source of funding was the easiest, less costly and readily available.

Another key finding of the study was that majority of the SME operators had never sourced for funds from formal financial institutions. They attributed this development to the bureaucratic procedures involved, high cost of borrowing and collateral requirement which most of them could not meet.

The study also revealed that those who sought financial assistance from the formal financial institutions and other quasi-financial institutions considered the credit offered them grossly inadequate. They contended that as a result of the under capitalization, poor record keeping and the low turnover that many of the SMEs record, the financial institutions were not willing to grant them substantial amounts of money which will suffice for their needs. 


\subsection{Challenges Facing SMEs in the Tamale Metropolis}

This sections discusses the factors that affect the performance of SMEs in the Tamale metropolis. These factors are group into broad categories such as economic, administrative/legal, human resources and factors relating to energy or power supply.

\subsubsection{Effects of Economic Factors on the Performance of SMEs}

The study considered the effects of interest charges, taxes, access to inputs as well as the availability of market for their products.

On the part of interest charges on loans contracted from Commercial Banks, the study revealed that the respondents considered interest paid on loans to be unreasonably high. Most of the respondents were of the opinion that the high interest rates currently charged on loanable funds have made borrowing rather expensive to many SME operators. The study also revealed that taxes paid on goods and services were unreasonably high. The respondents lamented this development and contended that high level of taxation on goods and services have led to price hikes resulting in low patronage for their products.

On the issue of access to raw materials (inputs), the study established that the respondents did not find it a problem giving their relative small size and nature of their offerings. They contended that their raw material requirement was not much a problem to them. As regards accessibility to market for their products, the study established that most of the respondents did not find it problematic getting customers for their products. As a result of their relative small size, they are able to carve a niche in the market place.

\subsubsection{Effects of Administrative/Legal Factors on the Performance of SMEs}

With respect to legal/administrative factors, the study established that SMEs operating in the Tamale metropolis did not get the needed support or incentives which are critically needed to enhance the performance of their businesses.

\subsubsection{Effects of Energy/Power Supply on the Performance of SMEs}

On the issue of cost of energy and power supply, the study established that cost of energy was unreasonably high. The study also revealed that erratic power supply being experienced in recent times was adversely affecting the smooth operations of their businesses.

\subsubsection{Effects of Human Resource Factors on the Performance of SMEs}

With regard to the availability of personnel for the day to day administration of their businesses, the study revealed that SME operators did not consider it a major headache. As a result of their relatively small size coupled with the informal nature of their operations, the SME operators claimed they did not have problems with hiring personnel and those often hired were relatively stable. This assertion could be true especially in recent times where unemployment rates are on the ascendency.

\subsubsection{Operational Constraints of NBSSI}

The study revealed that operation of NBSSI is constrained by a number of factors including inconsistent donor support which limits the financial resources of the board. Closely related to this, is that the board also lamented the inconsistency nature of funds being received from the government. Another constraint was the undue political influence in the affairs of the board which limits its autonomy to function effectively.

\section{Conclusion}

The study concluded that lack of access to credit from the mainstream commercial banks and other credit lending institutions, coupled with macro-economic factors such as high interest rates and taxes on goods and services adversely affected the performance of SMEs in the Tamale metropolis. The study also concluded that lack of Government support for SME operators in the metropolis was also responsible for their abysmal performance. Other key factors that were found to affect the performance of SMEs in the Tamale Metropolis positively included access to personnel, availability of raw materials and access to market for their products.

\section{Recommendations}

Based on the findings of the study, the researcher believes that when the below recommendations are implemented it will enhance the performance of the SMEs in the Tamale metropolis.

\subsection{Capacity Building for SME Operators}

The government and other civil society organizations should endeavour to provide basic business management and financial literacy training to SME operators within the Tamale Metropolis as this will enable them make well informed investment decisions. This will improve their entrepreneurial skills that will enable them to recognise and exploit the available business opportunities both locally and internationally.

\subsection{Accessibility of Financial Resources}

The study established that most SMEs operators prefer to use personal savings to start their own businesses because they consider it extremely difficult to access funds from commercial banks due to strict requirements such as 
collateral security and strict repayment terms. Therefore, the study recommends that banks and other quasi financial institutions should come up with innovative ways of making access to funds easy for the SMEs.

\subsection{Provision of Business Information to SME Operators}

There is the urgent need for Government and civil society organizations to make information readily available to SMEs so as to bridge the knowledge gaps of these operators. Many SME operators in the metropolis still have no access to relevant business information about opportunities that are available locally and globally. It is therefore recommended that relevant stakeholders organize seminars and business drills for these SMEs so that they will be able to perform better.

\subsection{Government Policy and Regulations}

The study established that the government's policy and regulations has a great influence on the performance of SMEs in the metropolis. Therefore, the study recommends that the government should come in as quickly as possible to make policies that will ensure the growth and expansion of the SMEs. The researcher believes the policy reforms will help in addressing the myriad of constraints such as high taxes, high interest rates, high electricity tariffs and the difficulties faced in accessing credit from formal financial institutions which are impeding the performance of the SMEs.

\subsection{The Need for Attitudinal Change}

The researcher gathered from the study that many SME operators did not take their businesses serious. They exhibited behaviours which were at variance with business ethics. Some of the negative bahaviours displayed included lateness to work, poor records keeping, disrespect for customers, and personal holidays occasioned by out-doorings and weddings, to mention a few. The study recommends that the SME operators change their current attitudes to their businesses and adopt positive work behaviours that will engender the growth of their businesses.

\subsection{Increasing the Capacity of NBSSI}

In order for the NBSSI to function effectively, the researcher recommends that government increase the capacity of the board to operate. In doing this, the government should ensure that funds are regularly and consistently released to NBSSI. This will enhance their financial capacity to operate. To add to this, it is also important for the government to limit its influence in the operations of NBSSI. This is important to ensure that the activities of the board are not unduly influenced.

\section{References}

i. Abor J. and Quartey, P. (2010), 'Issues in SME Development in Ghana and South Africa', International Research Journal of Finance and Economics, 39: 218-28.ACCA (2010), Small Business: A Global Agenda

ii. Ackah, J and Vuvor, S. (2011) The Challenges faced by Small \& Medium Enterprises (SMEs) in Obtaining Credit in Ghana. Ghana.

iii. Andzelic, G., Dzakovic, V., Lalic., B., Zrnic, D. and Palcic, I. (2011). Evaluating the impact of environmental factors on the international competitiveness of Small and Medium sized Enterprises in the Western Balkans, African Journal of Business management, 5 (4), pp. 1253-1265

iv. Ayyagari, M., Demirgüç-Kunt, A. and Maksimovic, V. (2011), Small vs. Young Firms Across the World Contribution to Employment, Job Creation, and Growth, Policy Research Working Paper 5631 (The World Bank Development Research Group).BDRC Continental (2012), SME Finance Monitor Q3 2012: A Gold, Silver or Bronze Summer for SMEs?

v. Babbie .E. (2005): The Basics of Social Research, $3^{\text {rd }}$ edn. Wadsworth, Thompson Learning Inc. U. S. A.

vi. Barnett, V. (2002). Sample Survey: Principles and Methods (3rd ed.). London: Arnold.

vii. Bryman, A. (1989). Research Methods and Organisation. London: Unwin Hyman.

viii. Business Times. (1997) Training cuts the rate of failure. [Online] Available at: http://www.btimes.co.za/97/1026/survey/survey17.htm. Accessed: 2 April 2016.

ix. Checkland, P and Holwell, S (1998). Information, Systems and Information Systems - making sense of the field. Wiley \& Sons Ltd, Chichester, England

x. Chodokufa, K. (2009). An analysis of the business relationship between SMEs and insurance companies in the Nelson Mandela metropolitan area. Masters Dissertation, Faculty of Management and Commerce, University of Fort Hare, South Africa.

xi. Cloke, P., Cook, I., Crang, P., Goodwin, M., Painter, J and Philo, C (2004) Practising Human Geography London: Sage

xii. $\quad$ Cochran, W.G. $\left(1963,2^{\text {nd }}\right.$ ed.). Sampling Technique. New York: John Wiley and Sons, Inc.

xiii. Cofie, A. A (2012): The challenges of financing Small and Medium Scale Enterprises (SMEs) in the Ashanti region [a case study of Stanbic Bank (Gh) Ltd]

xiv. Cornelia, E. Z (2012). The problems and prospects of management of small-scale business in Nigeria [Masters Thesis] submitted to the University of Nigeria

xv. Dalberg, (2011). Report on Support to SMEs in Developing Countries through Financial Intermediaries in D. group (Ed.). Geneva: Dalberg Consultancy.

xvi. $\quad$ Darko, E. and Koranteng, K. (2015) Social Enterprise Landscape in Ghana. British Council Ghana. Accra.

xvii. Darkwah, S.K., Morrison, E., Gyimah, K. H., Berko, S. and Adusei, J (2013) A study of finance options for SMEs in Ghana:the case of savings and loans companies in the Ashanti region of Ghana. 
xviii. Dawson, C. (2007) A practical guide to research methods. A user-friendly manual for mastering research techniques and projects. United Kingdom.

xix. Duan, Y., Kinman, R. and Xu, M (2002). The use of decision support systems in SMEs. In S.S Burgess (Ed), Managing information technology in small business: Challenges and solutions (pp. 140-155).Hershey, PA: Idea Group Publishing.

xx. Edmiston, K. (2007). The Role of Small and Large Businesses in Economic Development, Economic Review, Second Quarter, pp. 73-97.

xxi. EIU (Economist Intelligence Unit) (2010), SMEs in Japan: A New Growth Driver?

xxii. European Commission (2005). The new SME definition: user guide and model declaration section. Brussels: Office for Official Publications of the European Communities.

xxiii. Fabunmi, B .C (2004). Small and Medium Scale Industries Nigeria: Problems, Prospects and Management Techniques; 2nd Ed. Akure, JBS Printing and Publishing.

xxiv. Gall, M. D. \& Borg, W.R (1996). Educational Research: An Introduction (6thed.). White Plains, NY: Longman Publishers USA.

xxv. Ghana Banking Survey (2013): Harnessing the SME Potential, pwc, Ghana.

xxvi. Ghatak, S. (2010), Micro, Small and Medium Enterprises (MSMEs) in India: An Appraisalwww.legalpundits.com/content_folder/SMEArti150610.pdf

xxvii. http://entrepreneurship.org/ /media/Entrepreneurship/Files/Entrepreneurship/Entrepreneurship/Six\%20L egal\%20Forms\%20of\%20Business.pdf (Accessed 24th April 2016)

xxviii. Hubbard, G. 2006. 'Measuring organizational performance: beyond the triple bottom line', Business Strategy and the Environment, 19: 77-191.

xxix. IFAD (2015) Training manual for the training of business development service of providers of the Rural Enterprises Programme (REP). Pentax Management Consultancy Services Limited. Accra

xxx. Institute of Distance Learning (2008) Research Methodology. The commonwealth of Learning. Canada.

xxxi. Kamunge, M. S., Njeru, A and Tirimba, O.I. (2014) factors affecting the performance of small and medium enterprises in Limuru town market of Kiambu County, Kenya International Journal of Scientific and Research Publications Vol. 4 (12) pp 1-20

xxxii. Katua, N.T (2014): The Role of SMEs in Employment Creation and Economic Growth in Selected Countries. International Journal of Education and Research. Vol 2 (12), pp. 462-472

xxxiii. Kayanula, D and P. Quartey (2000), The Policy Environment for Promoting Small and Medium Sized Enterprise in Ghana and Malawi, Finance and Research Development Programme Working Paper Series No.15

xxxiv. Khan, A.M. (2010) 'Effects of human resource management practices on organizational performance: an empirical study of oil and gas industry in Pakistan', European Journalof Economics, Finance and Administrative Sciences, 24: 158-175.

xxxv. Kongolo, M. (2010). Job creation versus job shedding and the role of SMEs in economic development, African Journal of Business management, 4 (11), pp. 2288-2295.

xxxvi. Korean Development Institute (2008): Building the Foundation for the Development of SMEs in Ghana

xxxvii. Kothari, C. R, (2004), Research Methodology Methods and Techniques New Age International (P) Limited, Publishers New Delhi

xxxviii. $\quad$ Kotler, P. and Keller, K.L (2006) Marketing Management (12 ${ }^{\text {th }}$ Ed.). Harvard Business publishing

xxxix. Lebas, M. \& Euske, K. (2002) A Conceptual and Operational Delineation of Performance, in Business Performance Measurement. UK: Cambridge University Press

xl. Lincoln, Y. S., \& Guba, E. G. (1985). Naturalistic Inquiry. Beverly Hills, CA: Sage.

xli. Mensah, F. B. O. and Marfo-Yardom, E. (2005) Entrepreneurship and Small Business Management. Ghana Universities Press. Accra

xlii. Mugenda, M. O. \& Mugenda, G. A. (2003). Research Methods. Nairobi: Acts Press

xliii. O'Leary, A. (2004). The Essential Guide to Doing Research. London: SAGE Publications.

xliv. Obeng, S.A. (2003).Introduction to Research Methods: Cape Coast: University Press, p.42.

xlv. Parker, R. et al (1995), small enterprises adjusting to Liberalization in five African countries, world bank discussion paper no. 271, Africa technical development series, the world bank, Washington D.C.

xlvi. Phillips, C. and Bhatia-Panthaki, S. (2007). Enterprise development in Zambia: Reflections on the missing middle, Journal of International Development, 9, pp. www.accaglobal.org.uk/content/dam/acca/global/PDF-technical/small-business/pol-afb-sbaga.pdf

xlvii. Pope, C. (2000). Social Science Research Methods. London: Allen and Unwinm.

xlviii. Rauf, A.M. (2007) HRM sophistication and SME performance: a case of readymade garment manufacturers and exporters in Lahore, Pakistan. Doctoral thesis, Department of Operations, Organization and Human Resources, Faculty of Management and Governance, University of Twente, Netherlands.

xlix. Stokes, D. and Wilson, N. (2006) Small business management and Entrepreneurship (6 ${ }^{\text {th }}$ ed.). Cengage Learning EMEA. United Kingdom

l. Tayie, S (2005) Research methods and writing research proposals. Pathways to Higher education project. Cairo University. Egypt

li. Tijani-Alawe, B.A. (2004) Entrepreneurship Process and Small Business Management, Industrial Science Centre, Sango - Ota. 
lii. USAID (2007) Booklet of standardized small and medium enterprises definition. Agency for International Development.

liii. Yamane, T. (1967). Statistics: An Introductory Analysis, 2nd Ed., New York: Harper and Row

liv. Yin, R.K. $\left(1994,2^{\text {nd }}\right.$ ed.). Case Study Research: Design and Methods. Beverly Hills: California, Sage. 